ReBEn, 35 : 102-130, 1982

\title{
ESTUDO DE ALGUNS FATORES QUE INFLUENCIAM O RENDIMENTO ESCOLAR DO ESTUDANTE DE ENFERMAGEM
}

\author{
Zélia Sena Costa* \\ Josete Luzia Leite* \\ Solange Sanchez *
}

ReBEn/10

COSTA, Z.S. e Colaboradoras - Estudo de Alguns Fatores que Influenciam o Rendimento Escolar do Estudante de Enfermagem. Rev. Bras. Enf.; DF, 35 : 102-130, 1982.

\section{INTRODUÇĀO}

A Universidade como um sistema aberto tem a responsabilidade de oferecer uma contribuição efetiva para 0 aperfeiçoamento das atividades de produção exercidas peo estudante. Sabe-se que, apesar de inúmeros estudos já efetuados em relação à formação de profissionais à nível superior, ainda não satisfazem as necessidades sentidas pelos estudiosos, educadores e pelo próprio mercado de trabalho.

Face à multiplicidade de atividades curriculares desenvolvidas pelo estudante de enfermagem durante o periodo do sua formação profissional, encontra-se ele, na contingência de executar tarefas de ordem administrativa, educativa, técnica, de pesquisa e outras. Somos cônscios de que todas elas são realizadas com a finalidade precípua de promover uma melhor atenção de enfermagem ao sliente. A enfermagem acompanha, dia a dia, o desenvolvimento científico e tecnológico, principalmente, a evolução da prcfissão em seus aspectos globais. Considerada como um sub-sistema integrador do sistema saúde, utiliza-se de métodos, normas e procedimentos específicos fundamentados mormente na filosofia e objetivos por ela definidos visando a conhecer e atender às necessidades básicas do homem.

E notório, pois, a grande responsabilidade da Universidade quanto à qualidade da preparação de profissionais de al'to nivel e, conseqüentemente, a qualidade da produção destes profissionais entregues à comunidade. Deste modo, a aceleração do desenvolvimento do País depende, em grande parte, dos profissionais egressos das Universidades.

Esta ação se estende, também, aos recursos humanos de nivel médio, visto que, é responsabilidade dos profissionais de nivel superior a preparação, a coordenação e a direção destes elementos.

* Professora do Curso de Enfermagem do Centro de Ciências da Saúde da Universidade do Rio de Janeiro - UNI-RIO. 
COSTA, Z.S. e Colaboradoras - Estudo de Alguns Fatores que Influenciam o Rendimento Escolar do Estudante de Enfermagem. Rev. Bras. Enf.; DF, 35 : 102-130, 1982.

A avaliação do rendimento escolar e o desejo de aperfeiçoamento contínuo do desempenho eficiente do estudante têm sido as freqüentes preocupaçōes de todos os educadores da área de enfermagem. Partindo dessa premissa, o aluno de enfermagem deve apresentar condições adequadas às requeridas pela natureza das atividades pertinentes à profissão.

As autoras pretendem demonstrar neste estudo o desempenho de um grupo de estudantes, seu rendimento escolar, relacionados aos principais fatores que interferem nesta problemática. Este estudo se prende às constantes observacōes efetuadas pelos docentes do Curso de Enfermagem da Universidade do Rio de Janeiro (UNI-RIO) quanto à reação deste grupo frente a determinadas sitliaçōes e o aparente desinteresse no desenvolvimento das atividades discentes, o que se supōe sejam decorrentes de inúmeros fatores, tais como: cansaço, baixa renda familiar, moradia distante e tempo insuficiente para o sono, repouso e o lazer.

Em decorrência dos resultados obtidos, as autoras sugerem a utilização de estratégias especiais no processo ensinoaprendizagem, orientação contínua pelos docentes responsáveis pelo alunado e uma sistematização na escolha das disciplinas e créditos correspondentes.

Baseadas nessas consideraçōes, elaborou-se este trabalho, visando aos seguintes OBJETIVOS:

- proceder um levantamento dos alunos do Curso de Graduação em Emfermagem que exerçam outra atividade além do curso;

- identificar os diferentes fatores que possam interferir no processo ensino/aprendizagem;

- detectar, junto aos enfermeiros supervisores, a quantidade do desempe- nho do elemento da sua equipe que estuda enfermagem;

- investigar as causas prováveis do desempenho inadequado do aluno de enfermagem face ao seu rendimento escolar;

- caracterizar a natureza da atividade remunerada e a sua influência no desempenho das atividades curriculares;

- estabelecer a relação existente entre a natureza da atividade remunerada $\mathrm{e}$ as atividades de aprendizagem;

- analisar as dificuldades advindas da atividade remunerada influenciando as atividades curriculares;

- estabelecer propostas alternativas que sirvam de padrão para o acompanhamento específico destes alunos.

\section{CONSIDERAÇÕES GERAIS}

De há muito o estudo das condições de aptidão requeridas para as principais profissões liberais foi alvo de estudo e investigação.

Já no século XVI, em 1591, Juan Dias Huarte publicou o seu famoso livro "EXAMEN DE INGENIOS PARA LAS CIENCIAS", no qual analisa, inteligentemente, o assunto.

Os problemas relacionados ao trabalho e as condições dos profissionais de enfermagem têm preocupado sobremodo os estudiosos na matéria, tanto que a Organização Internacional do Trabalho (OIT) e a Organização Mundial de Saúde (OMS), em reunião conjunta, em 1976, abordaram de modo eficaz e eficiente as "Condições de Trabalho e de Vida do Pessoal de Enfermagem".

PALMER (1976) define a Ergonomia como: o estudo científico da relação entre o homem e seu ambiente de trabalho (instrumentos, matérias-primas, métodos e organização do traba- 
COSTA, Z.S. e Colaboradoras - Estudo de Alguns Fatores que Influenciam o Rendimen-

to Escolar do Estudante de Enfermagem. Rev. Bras. Enf.; DF, 35 : 102-130, 1982.

lho). Relacionada a tudo isto está a natureza do próprio homem incluindo suas habilidades e capacidades de limitações. Correlacionados à ergonomia estão as relações interpessoais do homem, seus colegas, supervisores, seus dirigentes e sua família. Todos esses aspectis, muito embora façam parte do campo das ciências sociais não deverão ser omitidos, visto que desempenham um papel assaz importante para a solução de vários problemas desta ciência.

Conforme referências anteriores, a Enfermagem constitui um sub-sistema no Sistema de Saúde; o homem tem o seu papel definido no contexto, necessitando trabalhar em condições favoráveis e suas atividades deverão ser organizadas de forma a atender as exigências que as tarefas lhe impõem.

CARVALHO (1977) comunica à Classe sobre a $61 .{ }^{\mathrm{a}}$ Conferência da Organização Internacional do Trabalho (OIT) — "Condições de Trabalho do Pessoal de Enfermagem" - Refere, a autora, que em quase todos os países do mundo as condições de trabalho do pessoal de enfermagem não são satisfatórias. E acrescenta que a "diversidade de categorias de trabalhadores nesse campo aumenta a dificuldade de se planejar uma boa formação técnica e ético profissional para os elementos de cada uma delas". Ainda, a mesma autora enfatiza as conclusões da conferência, chamando atenção para o capítulo que trata do preparo de pessoal.

Sabe-se que em nosso meio as condições de trabalho para o pessoal de enfermagem, de um modo geral, não atendem às necessidades específicas da profissão.

Reconhece-se, também, que os requisitos exigidos para a formação de pessoal de enfermagem são específicos, requerendo dos candidatos saúde física e mental. Daí a necessidade de atenção e orientação, mais acurada, dos docen- tes ao alunado, durante todo o Curso. Entretanto, o aluno de enfermagem, como qualquer ser humano, pode ser oriundo de diferentes camadas sociais, inclusive a de baixo poder aquisitivo, necessitando, portanto, de condições para se subsistir ou, até mesmo, ser um arrimo de familia. Deste modo. é levado a procurar atividade remunerada, o que pode interferir, consideravelmente, nas suas atividades estudantis originando inúmeros problemas paralelos.

A procura de emprego desse grupo, em busca de melhores condições de vida e remuneração, leva o Ensino de Enfermagem a uma situação que pode se considerar complexa, principalmente, no que se prende ao desempenho e à qualidade.

Nas instituições hospitalares, o elemento fundamental deste sistema é o pessoal de enfermagem, constituindo o grupo mais numeroso e, geralmente, fazendo parte também deste sistema estudantes de enfermagem com atividades remuneradas, os quais podem ser utilizados em setores de alta complexidade, considerados estressantes, tais como: Unidades de Tratamento Intensivo, de Emergência, Centros Cirúrgicos e outros, substituindo, eventualmente, profissionais.

Outro desafio com que se deparam aqueles que militam no ensino da enfermagem é constituído pelo grupo que já trabalha na ocasião em que ingressa na Universidade, seja na área da Saúde ou fora dela. Em se tratando daqueles que atuam na área da Enfermagem, os problemas se apresentam nas mais variadas formas, face à natureza desta atividade, como, por exemplo: jornadas longas de trabalho, condições físicas $e$ ambientais precárias e tipo de tarefa que executam. Deste modo, o professor deverá utilizar estratégias diferenciadas para este grupo. 
COSTA, Z.S. e Colaboradoras - Estudo de Alguns Fatores que Influenciam o Rendimen-

to Escolar do Estudante de Enfermagem. Rev. Bras. Enf.; DF, 35 : 102-130, 1982.

Diante desta problemática, o aluno, certamente, já debilitadó por outras causas emocionais, psíquicas, sociais, acrescidas ao cansaço do trabalho e do estudo, poderá ser levado à fadiga e até ao stress.

A fadiga é tema discutido e pesquisado por uma gama de profissionais, tais como: fisiologistas, psicólogos, psiquiatras e antropólogos, médicos, enfermeiros e outros profissionais. Sob o ponto de vista da fisiologia, o problema tem sido estudado e pesquisado, sobretudo os efeitos decorrentes do excesso do trabalho muscular ressaltando a fixação dos recursos capazes de obviá-los na área. Quanto aos estudos da fadiga no campo da an'tropologia são muito mais vastos e se relacionam à verificação de certas culturas que se predispõem mais do que outras para o seu desencadeamento, a exemplo das estruturas competitivas de elevado índice de atrito social. Os antropologistas trabalham em estreita conexão com psicólogos sociais, médicos e psiquiatras.

A fadiga não é uma enfermidade, entretanto poderá causar no indivíduo mal-estar com alterações em seu estado psicossomático. Quando ela atinge o máximo e se caracteriza por estafa, os principais efeitos são os seguintes: diminuição de sensibilidade tátil, diminuição da velocidade de contrações, relaxamento ou contração dos músculos, descoordenação e imprecisão dos movimentos, diminuição da agilidade, da habilidade, da destreza e da força, enfraquecimento da atenção, da memória, da coordenação de idéias e da vontade. Esses efeitos acarretam diminuição de rendimen'to global, observados na produção, quer no aspecto qualitativo, quer no quantitativo.

TUTLLE e SCHOTTELIUS (1969) afirmaram que a fadiga, quando se apresenta, a eficiência diminui; para tanto recomendam-se períodos de descanso adequados para se conservar uma boa disposição física. No corpo humano, a sensação de fadiga não se deve confundir com a perda verdadeira das propriedades fisiológicas em conseqüência da atividade. A sensação mencionada, também chamada fadiga subjetiva, muitas vezes, não é senão um simples aborrecimento, enquanto que, fadiga objetiva é a perda fisiológica da capacidade de se continuar trabalhando com a mesma velocidade. Depende muito, também, das condições individuais: constituição e temperamento variável, inadaptação efetiva ao tipo de trabalho que desenvolve e, como conseqüência, baixa de produtividade na execução do trabalho do indivíduo.

MULLER-BURT (1973) afirmam não serem ainda conhecidas todas as causas de fadiga, mas qualquer que seja sua origem, fica um alerta para a necessidade do repouso e do lazer.

AGUIAR (1978) cita que as causas de fadiga estão relacionadas com o repouso inadequado, iluminação e ventilação deficientes, calor, ruído, tarefas desagradáveis, trabalho em ritmo inadequado, ausência de lazer, fumo e excesso de horas extras.

A área da saúde, atualmente, mantém um interesse crescente sobre o estudo deste problema como um dos fatores que mais afetam a saúde do homem. Modernamente, no âmbito profissional e dos negócios, a vida tem impelido o homem a constantes situações de expectativas e de tensões. f́bvio que evitar semelhan'tes problemas seria de todo impossível; no entanto, há métodos capazes de prevení-los, tais como: um período de trabalho diário bem planejado com tempo suficiente para o descanso e lazer, uma vida familiar social e religiosa feliz. Sabe-se que todos os seres vivos, constantemente estão expostos a tensões, o que se traduz pelo 
COSTA, Z.S. e Colaboradoras - Estudo de Alguns Fatores que Influenciam o Rendimento Escolar do Estudante de Enfermagem. Rev. Bras. Enf.; DF, 35 : 102-130, 1982.

desgaste a que está sujeitso o nosso organismo e que pode aumentar cada vez que um acontecimento agradável ou desagradável exacerbe a intensidade do nosso viver.

Em contraposição ao que geralmente se pensa, o stress não é uma simples tensão nervosa, nem mesmo o resultado de um transtorno nocivo, orgânico e funcional. O stress é o acompanhante invariável de todos os nossos impulsos orgânicos. algo que surge sempre que exigimos um esforço por parte do nosso organismo. $O$ paciente que se apresenta com hipertemia; um torcedor apaixonado por futebol ao apreciar uma partida decisiva; um estudante na expectativa de uma avaliação, todos eles se encontram em estado de tensão.

Os desportos poderão também nos levar à tensão, tanto da mente, como do físico. Este tipo de tensão que aumenta a capacidade do esforço muscular, denomina-se de estresse esporádico, socialmente aceito, voluntário e provocado. Há indivíduos que suportam melhor as tensōes do que outros, porém todos nós estamos predispostos a diminuir nossas forças se a pressão ultrapassar a certos limitas.

SELYE, em 1925, quando estudante de Medicina da Universidade de Praga, observou, pela primeira vez, em seus pacientes algo que denominou de stress, bem como de Sindrome Geral de Adaptação (SGA), concluindo pelos estudos realizados que as reaçōes emocionais apresentadas pelos seus pacientes não consistiam, apenas, em sindromes patológicas, mas, sim, tensōes que mais tarde denominaria de stress. Deste modo, considerou importante o estudo sobre o mecanismo da doença ao invés de focàlizar, exclusivamente, as manifestaçōes específicas de cada patologia. Dez anos mais tarde, trabalhando no Departamento de Biologia da Universidade McHill, de Montreal, procurou isolar um novo método de preparo desses extratos, observando que todos eles causavam uma síndrome caracterizada por:

a) aumento da cortex das glândulas supra-renais;

b) úlceras gastro-intestinais; e

c) involução do timo e dos gânglios linfáticos.

Concluiu, SELYE, numa simples conjectura, a possível ligação entre a intuição puramente especulativa e quase esquecida de seus dias de estudante, e as alteraçōes, experimentalmente, reproduziveis em animais de laboratório, as quais iriam servir de base para a teoria do stress. Deste modo, conectou o conceito clínico anterior com essas experiências para a conceituação do stress.

TURNER (1965) enfatiza estudos realizados, na Guerra da Coréia, em soldados americanos antes e depois do combate, demonstrando que os exames de sangue, saliva e urina, destes soldados que estiveram sob fogo intenso de artilharia durante 5 dias, com apenas $7 \%$ de mortes, encontravam-se em condiçōes bem piores do que aqueles que suportaram 18 horas de combate intenso durante as quais as baixas foram em torno de $70 \%$. Constatando-se que os soldados que combateram durante 18 horas apresentaram uma descarga e reserva supra-renal elevadas, enquanto aqueles que estiveram em frente de combate durante 5 dias mostraram-se em esgotamento grave e, conseqüentemente uma maior falência das suprarenais.

E oportuno, pois, recomendar-se que se deve adotar uma forma de vida saudável em que se possa desenvolver atitudes mentais que nos permitam assumir responsabilidades sem grandes angústias ou tensōes excessivas.

TURNER (1965) afirma que o sono é considerado uma das necessidades bá- 
COSTA, Z.S. e Colaboradoras - Estudo de Alguns Fatores que Influenciam o Rendimento Escolar do Estudante de Enfermagem. Rev. Bras. Enf.; DF, 35 : 102-130, 1982.

sicas do organismo. E o momento em que os tecidos do corpo aproveitam para reparar suas perdas. Sabe-se que todo ser humano privado do sono durante um certo tempo poderá morrer. O homem não consegue permanecer mais do que 10 (dez) dias sem dormir, portanto, é uma necessidade que deve ser atendida em intervalos periódicos. Pode-se tomar como exemplo a pesquisa realizada na Western Electric Co. - com um grupo de operárias jovens que desenvolviam um trabalho manual ligeiro e que exigia destreza, com a finalidade de comparar o rendimento individual diário e o número de horas que estas operárias dormiram na noite anterior. Esta observação foi realizada durante seis meses, de onde se pôde concluir que o sono, como uma necessidade básica do organismo, è tão importante que serve para determinar o poder de produção do indivíduo. Sob o ponto de vista de redução da capacidade para o trabalho, algumas dessas operárias poderiam suportar melhor a perda do sono do que outras.

\section{METODOLOGIA}

A metodologia empregada para a elaboração do presente trabalho constou de um levantamento entre profissionais atuantes em 5 (cinco) instituições hospitalares de caráter governamental, docentes e estudantes do Curso de Graduação em Enfermagem da Universidade do Rio de Janeiro (UNI-RIO), com a finalidade de obter informações sobre o desempenho do servidor estudante de enfermagem, como também sobre as dificuldades por eles encontradas no trabalho e as causas possiveis que poderão influenciar no seu rendimento escolar.

Com base nos objetivos elaborados, o estudo se desenvolveu obedecendo às seguintes etapas: a) levantamen'to bibliográfico;

b) elaboração de questionário;

c) dimensionamento da amostra;

d) tabulação dos dados;

e) análise dos dados levantados; e

f) comentários.

O Universo para o estudo foi constituído de estudantes do $3 .^{\circ}$ ao $9 .^{\circ}$ período de Graduação, enfermeiros de 5 (cinco) instituições hospitalares do tipo governamental e docentes de enfermagem da UNI-RIO.

O levantamento preliminar identificou 407 estudantes, 100 enfermeiros, 50 docentes, chegando-se a uma amostra de 376 estudantes, 42 enfermeiros, 50 docentes, assim distribuídos: 376 alunos do Curso de Graduação; 42 enfermeiros nos hospitais do Rio de Janeiro e 50 docentes do Curso de Enfermagem da Universidade do Rio de Janeiro.

Além dos questionários, utilizou-se, também, dados secundários provenientes dos registros e arquivos dos Departamentos de Enfermagem e da Secretaria Escolar do Curso de Enfermagem da UNI-RIO, a fim de adquirir subsídios sobre o rendimento escolar.

\section{INTERPRETAÇAOO DOS DADOS}

Foram respondidos pelos estudantes 376 questionários, sendo que a maioria dos respondentes, isto é, $79,8 \%$, é do sexo feminino (300) e $20,2 \%$ do sexo masculino (76). A faixa etária predominante é de 20 a 30 anos, constituindo o percentual de $60 \%$, ou seja, 225 estudantes. Quanto ao estado civil, $74,2 \%$ (279) são solteiros e apenas $22,7 \%$ (186) são casados (Tabela I).

A situação do estudante e $m$ relação a trabalho e estudo é verificada na Tabela II; numa visão global, 59,8\% (225) estudam exclusivamente, enquanito que $40,2 \%$ (151) estudam e trabalham. Com base no númoro dos que não trabalham, 
COSTA, Z.S. e Colaboradoras - Estudo de Alguns Fatores que Influenciam o Rendimento Escolar do Estudante de Enfermagem. Rev. Bras. Enf.; DF, 35 : 102-130, 1982.

isto é, $59,8 \%$ (225) observa-se que destes $79,8 \%$, ou seja. 178 , pretendem ainda trabalhar, e $28,8 \%$ (47) não pretendem.

A Tabela III demonstra que dos estudantes que trabalham, $80,3 \%$ (121) atuam na área da enfermagem, enquanto que $15,1 \%$ (23) atuam em serviço burocrático e $4,6 \%$ (7) em outras atividades. A mesma tabela evidencia ainda os itens referentes à jornada de trabalho e a turnos correspondentes. $\mathrm{Na}$ área de enfermagem, a jornada predominante é a de $47,7 \%$ (72) que corresponde a 12 horas de trabalho com 60 de descanso. Seguindo-se a de 12 horas de trabalho por 36 horas de descanso, $33,1 \%$ (50). A jornada correspondente a plantão de 24 horas corridas constituiu um percentual de $14 \%$ (21) e a de 6 a 8 horas diárias compreendem respectivamente $3,9 \%$ e $1,3 \%$ (6 e 2 ), neste grupo, situam-se os estudantes que ora fazem in'ternato em instituições hospitalares. Quanto ao turno da atividade, o preferido é o noturno $80,1 \%$ (121), logicamente, por desenvolverem o curso am tempo integral. Os turnos diurnos e vespertinos correspondendo a $14,6 \%$ (22) e $5,3 \%$ (8) constituem a minoria. Enquanto que os enfermeiros supervisores $92,8 \%$ (39) trabalharam em tempo integral e $7,2 \%$ (3) em tempo parcial (Tabela IV).

Nas Tabelas V e VI observa-se que os enfermeiros supervisores $100 \%$ (42) que responderam aos itens referentes ao desempenho e atitude do servidor estudante $33,4 \%$ (14) consideram o desempenho deficiente, enquanto que $21,4 \%$ (9) responderam satisfatório, $21,4 \%$ (9) acharam bom, apenas $11,9 \%$ (5) consideram o desempenho excelente. No entanto, $11,9 \%$ (5) foram de opinião que o desempenho é insuficiente. No que se refere à atitude, 64,3\% (27) dos supervisores interrogados alegam que o servidor apresenta-se cansado, $11,9 \%$ (5) desinteressado, $9,5 \%$ (4) interessado, $4,8 \%$
(2) ativo e $2,4 \%$ (1) omisso, $7,1 \%$ (3) sem resposta.

Depreende-se daí, pela Tabela VII, que, dentre as dificuldades enumeradas pelos acadêmicos de enfermagem, para levarem a termo as atividades estudantis, $35,9 \%$ (135) alegam falta de tempo para dormir, 25,2\% (95) falta de tempo para estudar, $20,2 \%$ (76) dizem estar cansados, enquanto que, $18,7 \%$ (70) referem-se à situação econômica insuficiente. Estes dados vêm reforçar a preferência do grupo pelo serviço noturno, daqueles que realizam o curso em tempo integral.

$\mathrm{Na}$ mesma linha de pensamento está a afirmação dos enfermeiros supervisores que citam como dificuldades encontradas durante a realização de seus cursos, $66,6 \%$ (28) falta de condiçōes para acompanhar as tarefas estudantis; $28,6 \%$ (12) trabalhar e estudar e $4,8 \%$ (2) trabalhar dentro da própria área, considerando-se a natureza do trabalho que exige do indivíduo um maior desgaste físico (Tabela VIII).

A opinião dos supervisores enfermeiros quanto à compatibilidade das atividades estudantis responderam $50 \%$ (21) que o estudante deveria apenas estudar, 33,3\% (14) que estes deveriam trabalhar em enfermagem e estudar, enquanto que $11,9 \%$ (5) afirmam, que estes deveriam trabalhar em atividades simples e estudar, $4,8 \%$ (2) deixaram de responder (Tabela IX).

Convém lembrar que a população dos supervisores enfermeiros estudada, que respondeu aos questionários, caracterizou-se pela conclusão do seu Curso de Graduação no período compreendido entre 1951 a 1979 e que deste grupo apenas, $47 \%$ (16) possuem habilitação e seis deles deixaram de colocar o ano da graduação, $1,2 \%$ (6) (Tabela X).

A faixa etária predominante destes enfermeiros está situada entre 30-40 anos, isto é, $28,6 \%$ (12) (Tabela XI). 
COSTA, Z.S. e Colaboradoras - Estudo de Alguns Fatores que Influenciam o Rendimento Escolar do Estudante de Enfermagem. Rev. Bras. Enf.; DF, 35 : 102-130, 1982.

Estes, interrogadcs, se durante o seu curso de graduação exerciam outras atividades, $100 \%$ (42) responderam afirmativamente e destes, em relação aos turnos, $64,3 \%$ (27) desenvolviam suas atividades em serviços noturnos, 28,6\% (12) em serviço diurno, $4,8 \%$ (2) em serviço parcial e, apenas, $2,3 \%$ (1) em horário livre (Tabela XII).

No que tange aos docentes da UNIRIO, as parcelas são consideráveis daqueles que não trabalharam durante o curso, isto é, $72 \%$ (36) enquanto que trabalharam $28 \%$ (14) (Tabela XIII). O maior percentual justifica-se, em virtude destes docentes haverem realizado o seu Curso de Graduação na época em que as Escolas de Enfermagem mantinham regime de internato.

Observe-se que a maior freqüência da faixa etária (Tabela XIV) está compreendida entre 40 a 50 anos, $48 \%$ (24).

Pressupōe-se que dos $28 \%$ (14) que trabalharam estão na faixa etária de 20-30 anos, 20\%, o que pode ser justificado porque já havia nas Escolas de Enfermagem a opção do externato. Destes, também, a natureza do trabalho predominante foi a enfermagem $70 \%$ (35) seguindo-se de $16 \%$ (8) e $14 \%$ (7) em outras atividades (Tabela XV). E como demonstra a Tabela XVI, estes docerites não sentiram dificuldades em acompanhar as tarefas estudantis $70 \%$ (35.) e dos $30 \%$ (15) que sentiram dificuldades, estas giraram em torno de cansaço $67 \%$ (10) e situação econômica insuficiente $33 \%$ (5). Isto porque sabese que aqueles que cursavam enfermagem recebiam amparo especial dos superiores ou facilidade nos horários quando servidores, ou mesmo bolsas de estudo o que supria, certamente, as dificuldades existentes.

Na opinião dos docentes, o estudante que trabalha, geralmente, sofre influências da área que atua sobre a sua vida estudantil $90 \%$ (45) e $10 \%$ (5) acham que não (Tabela XVII). Todos os dccentes observam que o rendimento escolar dessas pessoas que trabalham e estudam estão entre: deficiente $-56 \%$ (28), insuficiente $-28 \%$ (14) e bom $16 \%$ (8) (Tabela XVIII). Na Tabela XIX verifica-se as diferentes atitudes dos estudantes observadas pelos docentes em salas de aula, laboratório ou mesmo no ensino clinico - $64 \%$ (32) apresentamse cansados, $32 \%$ (16) desinteressados $\theta$ $4 \%$ (2) interessados. Comparando-se estes dados com os da Tabela XX observa-se que $84 \%$ (42) de docentes são de opinião que o estudante deve apenas estudar e $16 \%$ (8) trabalhar em atividades simples.

No que se refere aos estudantes que trabalham durante a realização do curso para o seu próprio sustento o percentual é evidenciado em $39,3 \%$ (148) sendo que $60,7 \%$ (228) não exercem atividades remuneradas para sua subsistência (Tabela $\mathrm{XXI}$ ). Pressupõe-se que estes são os que seus gastos são financiados pela família, outras instituiçōes, inclusive crédito educativo, cujo percentual é significativo, isto é, $58,7 \%$ (221) (Tabela XXII). Observa-se, também, na Tabela XXIII que os $30 \%$ (105) de estudantes contribuem, parcialmente, para o sustento de sua família, enquanto que $70 \%$ (271) não contribuem para a renda familiar.

Com base nos demonstra'tivos do estudante que trabalha e alega dificuldades, para tal, a Tabela XXIV mostra que ele mesmo riconhece a impossibilidade de conciliar trabalho e estudo, $72,1 \%$ (271) consideram incompativeis as atividades trabalho e estudo, enquanto que $27,9 \%$ (105) acreditam nesta conciliação.

\section{COMENTÁRIOS}

O Curso de Enfermagem da UNIRIO tem por objetivo formar enfermeiros, proporcionando-lhes condiçōes para 
COSTA, Z.S. e Colaboradoras - Estudo de Alguns Fatores que Influenciam o Rendimento Escolar do Estudante de Enfermagem. Rev. Bras. Enf.; DF, 35 : 102-130, 1982.

planejar, executar e supervisionar a assistência de enfermagem.

De acordo com a legislação vigen'te - Resolução n. ${ }^{\circ} 4 / 72$ do MEC-CFE e Parecer n. ${ }^{\circ}$ 163/72 -, a carga horária minima do Curso de Graduação em Enfermagem no País é de 2.500 horas para o tronco profissional comum, incluindo o pré-profissional. Após a realização do tronco profissional comum o concludente poderá optar para as habilitações em Enfermagem Médico-Cirúrgica, Enfermagem de Saúde Pública, Enfermagem Obstétrica, com a carga horária minima de 500 (quinhentas) horas cada uma. $O$ ano acadêmico da UNI-RIO compreende 2 (dois) periodos, por semestre, com o minimo de 90 (noventa) dias úteis, ou seja, 15 (quinze) semanas por semestre. O trabalho escolar tem como unidade básica o Sistema de Créditos, havendo diferença entre o crédito teórico e o prático. O estudante poderá escolher as disciplinas de um semestre para realização de sua matrícula. No entanto, de acordo com o que estabelece a legislação vigente, o aluno de Enfermagem deve realizar o seu curso no período de 4 (quatro) a 6 (seis) anos

Reconhece-se que o ensino da Enfermagem só pode ser ministrado com a colaboração de outras ciências, num espírito interdisciplinar e deve ser desenvolvido num perfeito relacionamento entre a teoria e a prática. Porém, não somente a prática ou apenas a teoria, mas, sim, uma teoria da prática. Isto significa que a experiência (prática) sempre ocorre a partir de uma teoria e que o questionamento teórico significativo deve sempre partir de preocupações e necessidades práticas.

No Curso de Graduaçāo em Enfermagem da UNI-RIO, procura-se desenvolver no alunado um ensino de caráter instrumental (o auxílio que a teoria presta à solução dos problemas práticos) acompanhado de um espírito crítico que questiona continuamente a prática. Deste modo, o universitário consciente do problema, deve procurar um constante relacionamento, tanto entre as disciplinas teóricas e as práticas, como, também, entre o seu estudo, como um todo, e a realidade social em que vive.

Os docentes da UNI-RIO procuram propcrcionar um estudo fundamentado na realidade, generalizando-o, de maneira que o aluno possa obter conhecimentos gerais e uma instrumentalização básica, adequada, que lhe permita, através de um esforço próprio de operacionalização deste instrumental enfrentar os problemas de uma realidade modificada, com a qual defrontar-se-á ao sair da Universidade. Para tanto, quando os recebemos do ciclo básico, intentamos incutir em sua mente, no inicio do $3 .^{\circ}$ periodo, que a vida universitária será embasada de aulas teóricopráticas, seminários, trabalhos científi$\cos$ e discussōes em grupos. O tempo empregado para a realizaçāo destes estudos será integral, não havendo um hiato teórico, distante da vida real do estudante. O seu trabalho intelectual deve ser fundamentado em conhecimentos mais profundos e de um aperfeiçoamen'to da realidade da comunidade universitária.

Face a todas estas considerações sobre o desenvolvimento do sistema de ensino do Curso de Graduação em Enfermagem da UNI-RIO e da natureza do processo ensino/aprendizagem requer do aluno, de uma maneira geral, dedicaçāo integral para os estudos, impossibilitando-o muitas vezes de assumir atividades e responsabilidades paralelas.

Levando-se em conta, ainda, que na área da enfermagem as condições de trabalho, fatores ambientais, jornada de trabalho, alimentaçāo, planejamento de tarefas diárias, nem sempre sāo favoráveis ao desenvolvimento das atividades específicas, poderá ocorrer, deste modo, uma sobrecarga nas funçōes orgânicas 
COSTA, Z.S. e Colaboradoras - Estudo de Alguns Fatores que Influenciam o Rendimento Escolar do Estudante de Enfermagem. Rev. Bras. Enf.; DF, 35 : 102-130, 1982.

do indivíduo, advindas do esforço despendido, não somente pelas atividades exercidas, como, também, pela ausência de repouso, sono, lazer e outros fatores circunstanciais, acrescidos dos problemas inerentes à vida moderna. Como se pode observar, o aluno que estuda e trabalha, comparado àquele que apenas estuda encontra-se em absoluta desvantagem com este, podendo, muitas vezes, ser levado ao cansaço, à fadiga, à estafa, ao estresse e até mesmo a outros problemas mais graves, conseqüentemen'te, o seu rendimento escolar sofrerá influência desta problemática.

- Conforme se pode observar nas tabelas apresentadas, as informaçōes são compativeis e oportunas sobre alguns aspectos da situaçāo escolar dos estudantes de Enfermagem.

Com base nos resultados obtidos mediante os diversos recursos: fichas de cadastro, de observaçāo, de ocorrências e mapas de avaliação de aprendizagem, existentes nos Departamentos do Curso de Enfermagem e da Secretaria Escolar, levantamos os dados essenciais para traçarmos o perfil e avaliarmos o desempenho global do estudante em apreço.

Quando nas propostas alternativas sugeriu-se a estratégia de "promover a integraçāo do estudante na comunidade universitária", nossa meta era a de favorecer mudanças no comportamento desses estudantes. O primeiro passo seria a previsão das experiências de aprendizagem, em função do que antes decidiu-se - compatibilizar a vida escolar com outra atividade. Deste modo, planejou-se uma metodologia de ensino especial (atendendo às diferenças individuais) onde se procedeu à avaliação sobre a viabilidade e adequaçāo das estratégias propostas, considerando-se eficaz aquela que conduz aos objetivos, visados em menor prazo e menor custo.
Note-se que a fase do planejamento exige dos docentes inúmeras decisōes, particularmente no que concerne às técnicas e à instrumentação utilizadas no processo ensino/aprendizagem.

Deste modo, observou-se em intervalos regulares o progresso desses estudantes e pôde-se, então, com maior segurança, avaliar as necessidades individuais com o propósito de corrigir possíveis deficiências e, se necessário, formar-se um grupo especial dentro da turma.

Urge, pois, uma tomada de posição dos docentes quanto ao planejamento e às decisōes do grupo em referência, visto que tais fatores irão afetar a formação do enfermeiro. Sabe-se que o planejamento adequado ao ensino é o primeiro passo para o atendimento dos anseios e dos propósitos dos órgãos formadores e, conseqüentemente, a melhoria qualita'tiva da produção destes profissionais que serāo entregues à sociedade.

Sem maiores pretensões, a nossa intenção é a de alertar aos docentes e aos enfermeiros da área assistencial sobre o tema e motivá-los, a fim de que futuras discussōes surjam sobre o assunto, o que, certamente, será de vital importância para o ensino da enfermagem no Brasil.

\section{PROPOSTAS ALTERNATIVAS}

Diante da problemática em questão e para operacionalizaçāo das estratégias, optou-se pela apresentação do algumas propostas alternativas que possam contribuir para um modelo de ação específica compativeis com as necessidades do ensino.

A utilização das propostas alternativas implica na observância dos seguintes principios:

- Valorizar o estudante de Enfermagem como um ser biopsicossocial; 
cosTA, Z.S. e Colaboradoras - Estudo de Alguns Fatores que Influenciam o Rendimento Escolar do Estudante de Enfermagem. Rev. Bras. Enf.; DF, $35: 102-130,1982$.

- Promover meios para uma relação docente/discente satisfatória;

- Orientar o estudante quanto ao planejamen'to adequado da sua vida escolar;

- Sistematizar, no ato da matrícula, a escolha do número de disciplinas ? serem cursadas, obedecendo os prérequisitos;

- Promover a integração cio esiüudante na comunidade universitárı:

- Orientar o estudante na escolha do emprego ou atividade remunerada, a fim de ccmpatibilizá-lo com a vida escolar;

- Preparar o aluno para enfrentar, naturalmen'te, as avaliaçōes da aprendizagem, sem as preocupaçōes e as tensōes que lhes impōem o sistema tradicional de ensino;

- Acompanhar o aluno, de um modo efetivo, a fim de promover uma participação ativa e permanente no processo ensino/aprendizagem.

Como base nos principios referidos e nos fatores identificados as autcras elaboraram propostas alternativas a serem utilizadas junto ao estudante que trabalhe (em anexo).

\section{CONCLUSŐES E SUGESTŌES}

Diante do exposto e dos fatores identificados mediante os instrumentos aplicados na pesquisa realizada, as autoras propōєm para a implementação nos Cursos de Graduação em Enfermagem, algumas estratégias scbre a matéria, sugerindo que:

- se promova maior integração do órgão Formador x Órgão Empregador, a fim de estabelecer critérios para o desenvolvimento adequado das tare- fas $\varepsilon$ serem $d$ isempenhadas pelo aluno que exerse atividade remunerada;

- o estudante receba orientação docente no ato da matrícula, quanto às disciplinas a serem cursadas, como, também, sobre a organização de sua vida escolar;

- se mantenha nos Cur'sos de Graduação professores orientadores com vistas ao acompanhamento efetivo do aluno;

- os responsáveis pelos serviços assistenciais envidem esforços junto aos ćrgãos de direção, a fim de propiciarem condiçōes favoráveis de trabalho;

- se reestude os padrōes minimos que estabelecem as diretrizes para o funcionamento satisfa'tório de um serviço de enfermagem, principalmente quanto às condiçōes ambientais e jornadas de trabalho;

- seja constante a preocupação dos responsáveis pelas equipes de trabalho de enfermagem no que se refere a propiciar meios junto aos órgãos competentes para forneser uma alimentação adequada ao seu pessoal, face ao tipo de atividade que exerce;

- tanto os Órgãos Empregadores como os Órgãos Formadores promovam oportunidades para a realização de atividades de lazer como medida preventiva das tensōes;

- se fomente, junto às Empresas, a necessidade de se oferecer oportunidades para o estudante participar como bolsista em seus programas de trabalho;

- os docentes e enfermeiros de Instituiçōes Empregadoras procedam estudos mais acurados sobre a matéria. 
COSTA, Z.S. e Colaboradoras - Estudo de Alguns Fatores que Influenciam o Rendimento Escolar do Estudante de Enfermagem. Rev. Bras. Enf.; DF, 35 : 102-130, 1982.

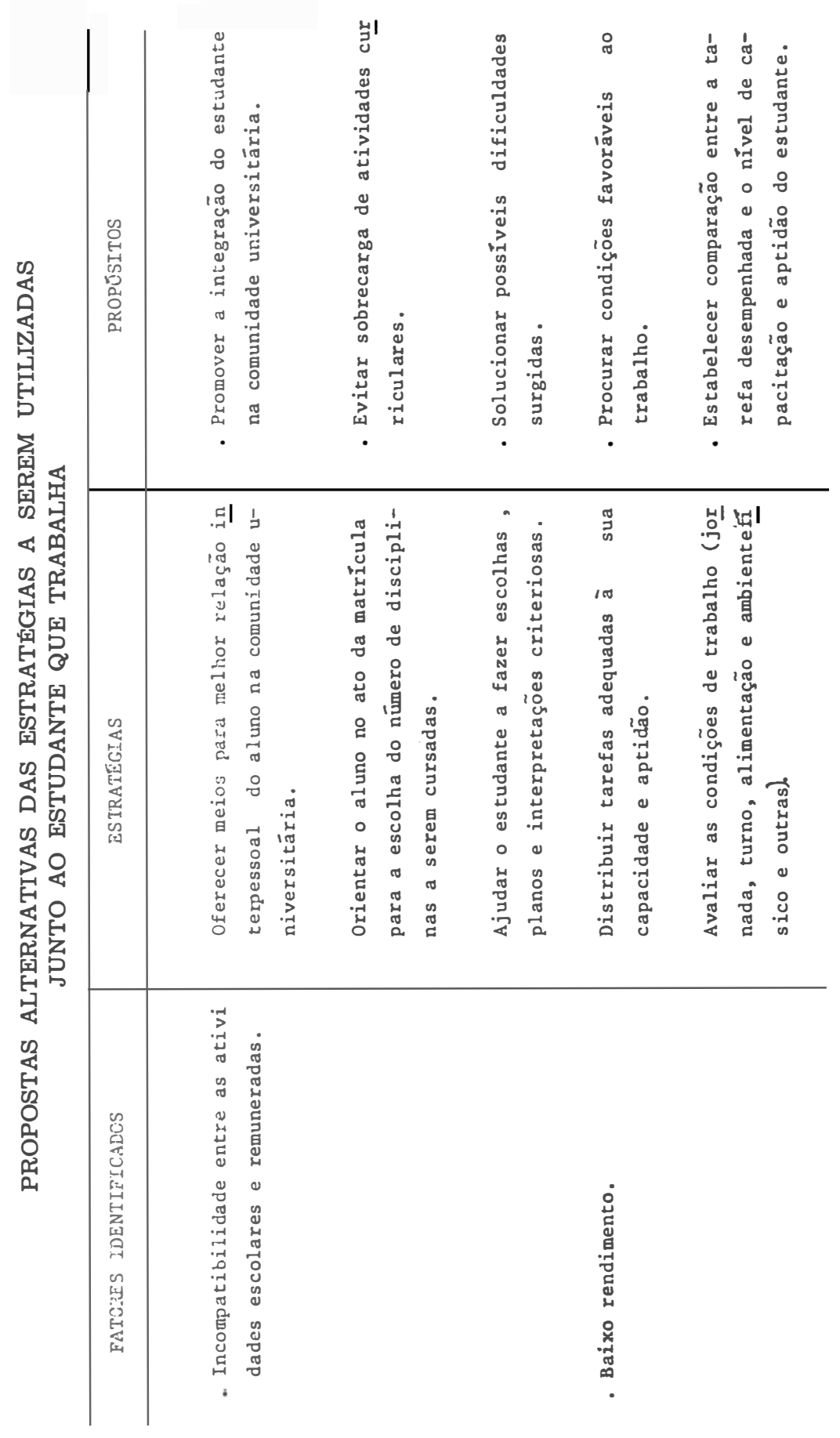


COSTA, Z.S. e Colaboradoras - Estudo de Alguns Fatores que Influenciam o Rendimento Escolar do Estudante de Enfermagem. Rev. Bras. Enf.; DF, $35: 102-130,1982$.

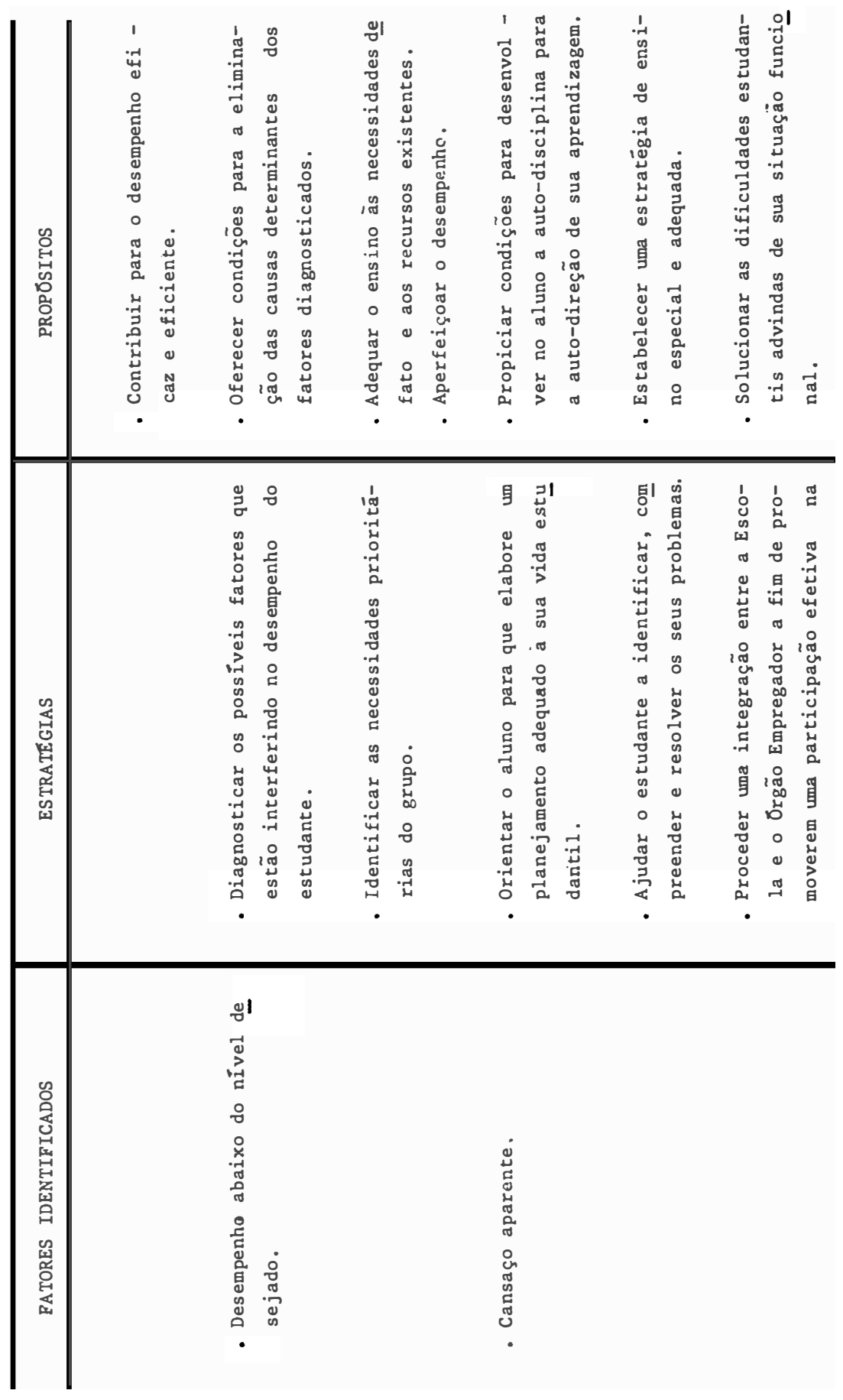


COSTA, Z.S. e Colaboradoras - Estudo de Alguns Fatores que Influenciam o Rendimento Escolar do Estudante de Enfermagem. Rev. Bras. Enf.; DF, 35 : 102-130, 1982.

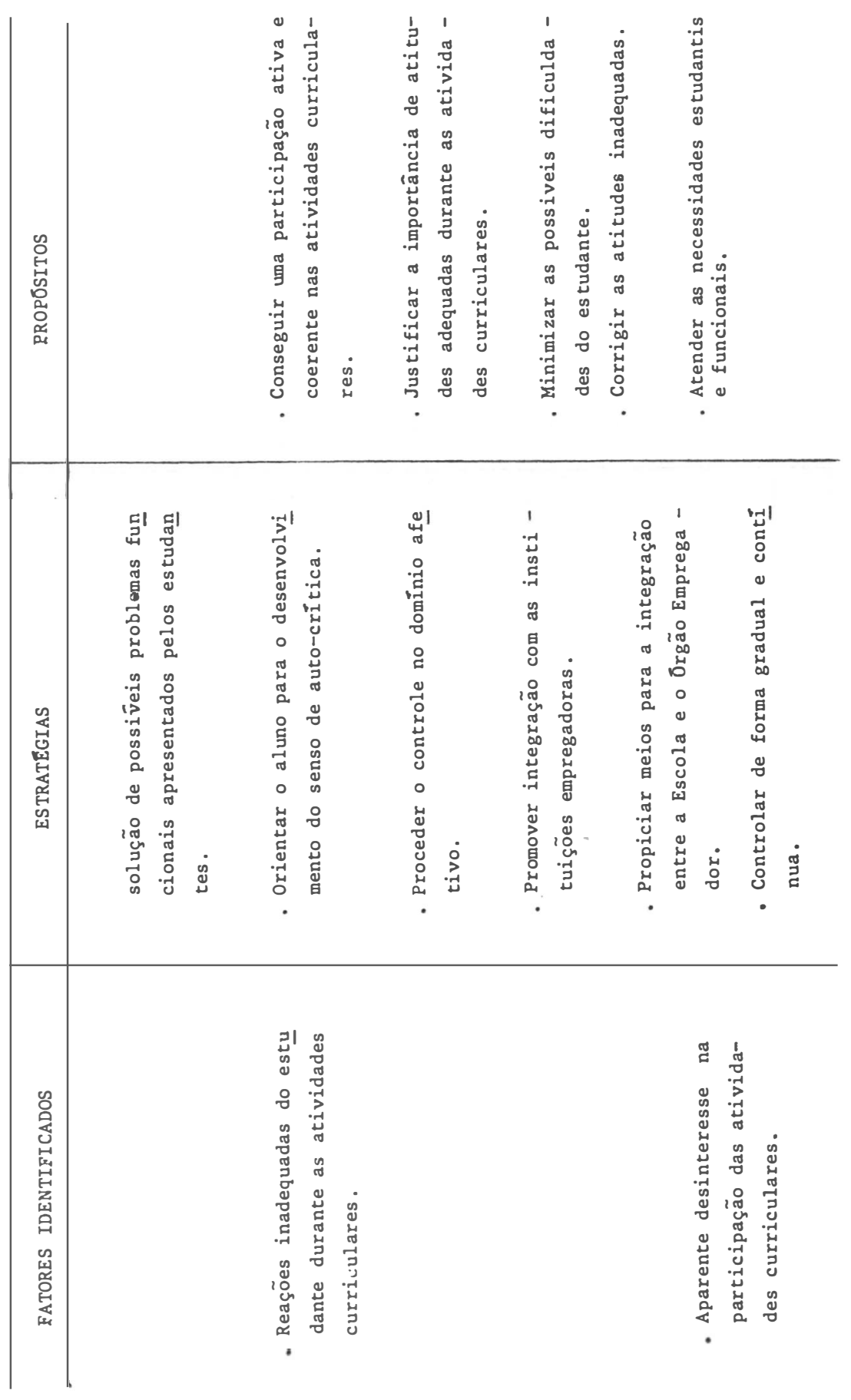


COSTA, Z.S. e Colaboradoras - Estudo de Alguns Fatores que Influenciam o Rendimento Escolar do Estudante de Enfermagem. Rev. Bras. Enf.; DF, 35 : 102-130, 1982

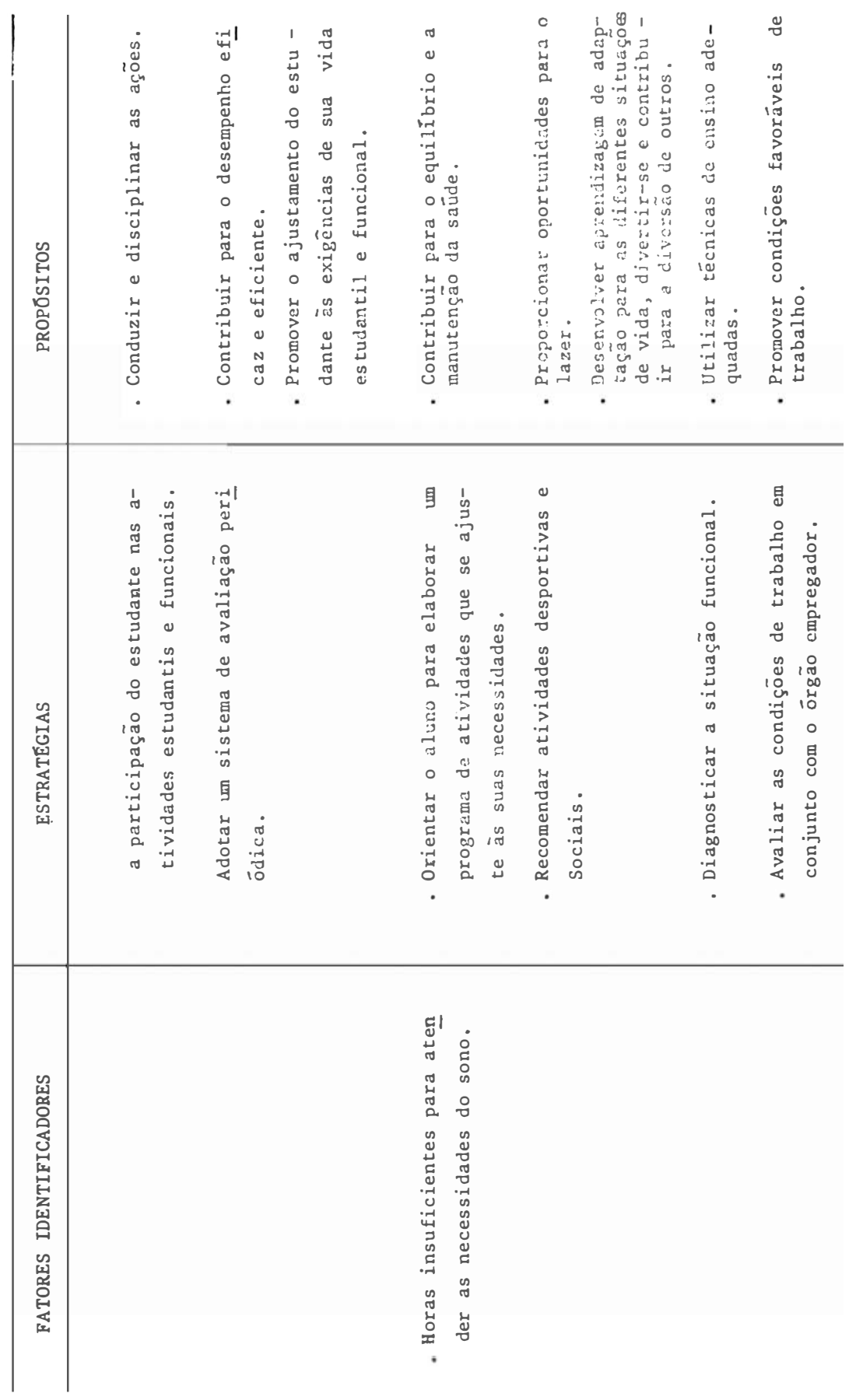


COSTA, Z.S. e Colaboradoras - Estudo de Alguns Fatores que Influenciam o Rendimento Escolar do Estudante de Enfermagem. Rev. Bras. Enf.; DF, 35 : 102-130, 1982.

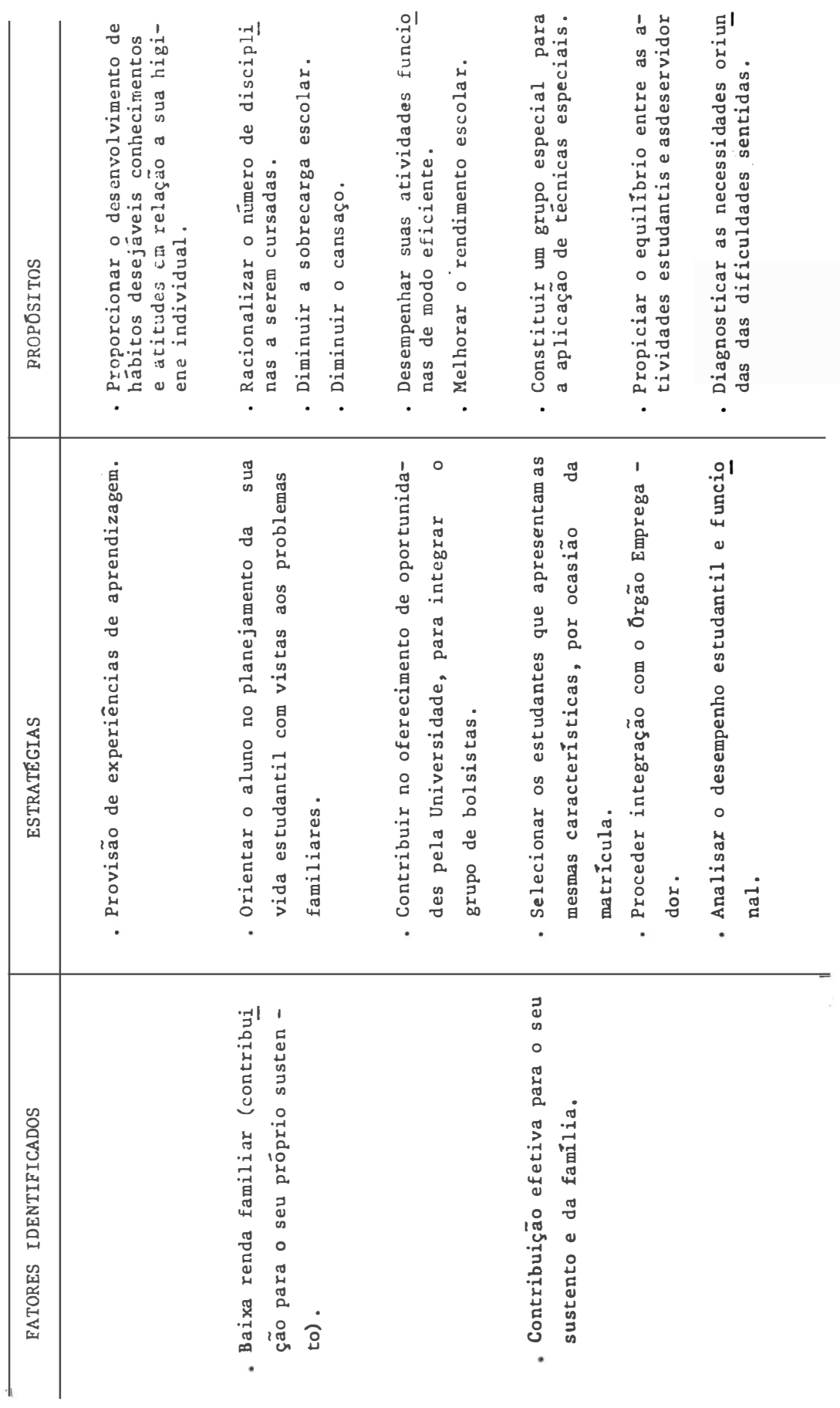


COSTA, Z.S. e Colaboradoras - Estudo de Alguns Fatores que Influenciam o Rendimento Escolar do Estudante de Enfermagem. Rev. Bras. Enf.; DF, $35: 102-130,1982$.

\section{B I B L IO G R A F I A}

1. AGUIAR, M. A. - Conferência sobre "Higiene e Segurança do Trabalho".

2. ALLEN, Robert - Industrial hygiene. Englewood Clifs, N. J., Prentice Hall, 1976

3. BART, Pierre - Ergonomia e organização do trabalho. In: Saúde Ocupacional, 6(21):6-11,1978.

4. BECK, Carlton E. - Fundamentos $f i$ losóficos da orientação educacional. São Paulo, EPU, EDUSP, 1977.

5. BRASIL. Ministério da Educação e Cultura - Elaboração e avaliação de programas de ensino. Brasília, MEC, 1976.

6. BRASIL. Ministério d a Educação e Cultura - Plano de avaliação: metodologia. Brasília, MEC, 1978.

7. BRASIL. Ministério da Educação e Cultura - Supervisão pedagógica e orientação educacional. Brasília, MEC, 1977.

8. BRASIL. Ministério do Trabalho e Previdência Social - Programa nacional de valorização do trabalhador. Rio de Janeiro, Departamento Nacional de Segurança e Higiene do Trabalho, 1973.

9. BRASIL. Ministério do Trabalho e Previdência Social - Segurança e higiene do trabalho. Rio de Janeiro, Departamento Nacional de Segurança e Higiene do Trabalho, 1971.

10. BRETAN, Jairo - Legislação sobre higiene e segurança do trabalho. In: Fundação Centro Nacional de Segurança, Higiene e Medicina do Trabalho. Curso de Medcina do Trabalho, v. 2, págs. 401-30.

11. CarValho, Amália C. - Condiçōes de trabalho do pessoal de enfermagem. In: Rev. Bras. Enf., 30 (3): 157-161, 1977.

12. CARVAlHo, Amália C. - Recursos humanos em enfermagem. In: Rev. Bras. Enf., 28(1), 1975.

13. Ergonomia: a ciência que torna o trabalho mais suave e seguro para o homem. In: Ind. e Produt., 7(74): 5-6, 1974.

14. Ergonomia: uma nova interpretação da relação homem-máquina. In: Rev. Senai, 35(134):8-12, 1979.

15. L'ergonomie: étude de l'atmosphére dans le lieu de travail. In: Travail et Maïtrise, 9:9-10, 1976.

16. FLEMING, C. M. - Psicologia do ensino. São Paulo, Nacional, 1971.
17. GILMORE, Charles Lee - Accident prevention and less control. New York, American Management Association, 1970.

18. O importante papel da ergonomia na postura do trabalho: In: Dirigente Industrial, 17(6):16-20, 1976

19. ISAAC, Mielnik - Higiene mental do trabalho. São Paulo, Artes Médicas, 1976.

20. LAVILLE, Antoine - Ergonomia. São Paulo, EDUSP, 1977.

21. LOFFREDI, Laís Esteves - Paradigme da orientação educacional. Rio de Janeiro, F. Alves, 1977.

22. MAURO, Maria Ivone Chaves, et alii - Fadiga e aspectos ergonômicos no trabalho de enfermagem. In: Rev. Bras. Enf. 29(1):7-18, 1976.

23. Medicina do Trabalho, investimento que dá lucro. In: Ind. e Desenv., 7(10): 12-6, 1974.

24. MITTIDIERI, Jorge - Segurança, higiene e medicina do trabalho. In: Ind. e Prod., 7(76):1921, 1974.

25. MURREL, Hywel - Homens e máquinas. Rio de Janeiro, Zahar, 1978.

26. PALMER, C. - Ergonomia. Rio de Janeiro, Fundação Getúlio Vargas, 1976.

27. SOUNIS, Emilio - Manual de higiene e medicina do trabalho. São Paulo, McGraw-Hill do Brasil, 1975.

28. STEGEMANN, Jürgen - Fisiologia do esforço. Rio de Janeiro, Cultura Médica, 1979.

29. STEGEMANN, Jeanne, et alii - Trabalho e saúde na indústria: riscos físicos e químicos e prevenção de acidentes. São Paulo, EPU, EDUSP, 1975 .

30. REZENDE, A. M. - Iniciação teórica e prática das ciências da educação. Petrópolis, Vozes, 1979.

31. TURNER, C. E. - Higiene del individuo y de la comunidad. México, Centro Regional de Ayuda Tecnica, 1965.

32. TURRA, Clódia Maria Godoy, et alii - Planejamento de ensino e avaliação. Porto Alegre, Ed. Meridional Emma, 1975.

33. VERDUSSEN, Roberto - Ergonomia: a racionalização humanizada do trabalho. Rio de Janeiro, Livros Técnicos e Científicos, 1978.

34. WHITTAKER, James D. - Psicologia. México, Interamericana, 1971. 
COSTA, Z.S. e Colaboradoras - Estudo de Alguns Fatores que Influenciam o Rendimento Escolar do Estudante de Enfermagem. Rev. Bras. Enf.; DF, 35 : 102-130, 1982.

\section{RESUMO}

As constantes dificuldades e o aparente desinteresse de um grupo de estudantes do Curso de Enfermagem, observados pelos docentes durante o desenvolvimento do processo ensino/aprendizagem, motivaram as autoras a procederem um estudo sobre os fatores $\mathbf{e}$ as possíveis causas determinantes dessa problemática.

Os instrumentos de avaliação do alunado, a análise dos questionários e a experiênsia docente constituíram subsídios para o desenvolvimento do trabalho.

Dos resultados obtidos, sugere-se a utilização de estratégias especiais de ensino, orientação efetiva do alunado e uma sistematização na escolha de disciplinas e créditos correspondentes.

\section{SUMMARY}

The constant difficulties and apparent disinterest of one group of students on the Nursing Course which have been observed by the teachers during the development of the teaching-learning process, have given the authors reason to carry out a study of these factors and possible causes of this problem.

The means for evaluating the students, the analysis of the questionnaires and the experience of the teachers contributed to the work's progress.

It is suggested that the use of special teaching methods, effective student orientation and a systematic plan in the choice of subjects and corresponding credits be implemented.

T A B E L A I

CENTRO DE CIÈNCIAS DA SAÚDE - CURSO DE ENFERMAGEM TOTAL DE ESTUDANTES, POR FAIXA ETÁRIA, ESTADO CIVIL E SEXO 1981

\begin{tabular}{|c|c|c|}
\hline D I S C R I M I N A Ç Ā O & TOTAL & $\%$ \\
\hline \multicolumn{3}{|l|}{ 1. FAIXA ETÁRIA } \\
\hline 20 & 114 & 30,3 \\
\hline $20-30$ & 225 & 60,0 \\
\hline $30-40$ & 30 & 7,9 \\
\hline+40 & 7 & 1,8 \\
\hline TOTAL & 376 & 100,0 \\
\hline \multicolumn{3}{|l|}{ 2. ESTADO CIVIL } \\
\hline SOLTEIRO & 179 & 74,2 \\
\hline CASADO & 86 & 22,7 \\
\hline OUTROS & 11 & 3,1 \\
\hline TOTAL & 376 & 100,0 \\
\hline \multicolumn{3}{|l|}{ 3. SEXO } \\
\hline MASCULINO & 76 & 20,2 \\
\hline FEMININO & 300 & 79,8 \\
\hline TOTAL & 376 & 100,0 \\
\hline
\end{tabular}

Fonte: Questionário respondido pelos estudantes do Curso de Enfermagem da UNI-RIO. 
COSTA, Z.S. e Colaboradoras - Estudo de Alguns Fatores que Influenciam o Rendimento Escolar do Estudante de Enfermagem. Rev. Bras. Enf.; DF, 35 : 102-130, 1982.

T A B E L A I I

CENTRO DE CIÊNCIAS DA SAÚDE - CURSO DE ENFERMAGEM SITUAÇÃO DO ESTUDANTE EM RELAÇÃO A TRABALHO E ESTUDO 1981

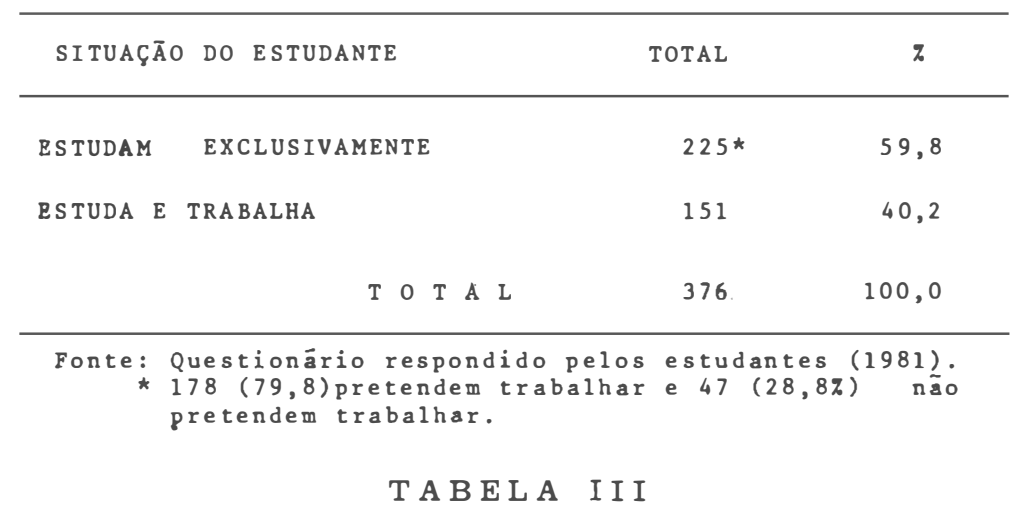

CENTRO DE CIÊNCIAS DA SAÚDE - CUREO DE ENFERMAGEM DISTRIBUIÇÃO DOS ESTUDANTES SEGUNDO AS ATIVIDADES DFSENVOLVIDAS ALEM DO CURSO DE ENFERMAGEM, JORNADA I TURNOS DE TRABALHO DESTAS ATIVIDADES

\begin{tabular}{lcr}
\hline D I S C R I M I N A \& A O & $\begin{array}{l}\text { NOMERO DE } \\
\text { ESTUDANTES }\end{array}$ \\
\hline 1. ATIVIDADES & 121 & \\
ENFERMAGEM & 23 & 80,3 \\
BUROCRATICA & 07 & 15,1 \\
OUTROS & 151 & 4,6 \\
& & 100,0 \\
T O T A & 06 & 3,9 \\
2.JORNADA DE TRABALHO & 02 & 1,3 \\
2.1 - 6 horas & 50 & 33,1 \\
2.2 - 8 horas & 72 & 47,7 \\
2.3 - 12 X 36 & 21 & 14,0 \\
2.4 - 12 X 60 & 151 & 100,0 \\
2.5 - P1antäo - 24 horas &
\end{tabular}

3. TURNO

$\begin{array}{rrr}3.1 \text { - DIURNO } & 22 & 14,6 \\ 3.2 \text { - NOTURNO } & 121 & 80,1 \\ 3.3 \text { - VESPERTINO } & 08 & 5,3 \\ 3.4 \text { - OUTROS } & & \\ \text { T O T A L } & 151 & 100,0\end{array}$

Fonte: Questionário respondido pelos estudantes do Curso de Enfermagem da UNI-RIO. 
COSTA, Z.S. e Colaboradoras - Estudo de Alguns Fatores que Influenciam o Rendimento Escolar do Estudante de Enfermagem. Rev. Bras. Enf.; DF, 35 : 102-130, 1982.

T A B E L A I V

HOSPITAIS DO RIO DE JANEIRO

NÚMERO DE GRADUADOS SEGUNDO O HORÁRIO EM QUE CURSOU ENFERMAGEM

1981

\begin{tabular}{|c|c|c|c|}
\hline REGIME DO CURSO & $N O D E$ & GRADUADO & $\%$ \\
\hline $\begin{array}{c}\text { INTEGRAL } \\
\ldots\end{array}$ & & 39 & 92,8 \\
\hline $\begin{array}{c}\text { PARCIAL } \\
\ldots\end{array}$ & & 03 & 7,2 \\
\hline $\begin{array}{lllll}\mathrm{T} & 0 & \mathrm{~T} & \mathrm{~A} & \mathrm{~L}\end{array}$ & & 42 & 100,0 \\
\hline
\end{tabular}

Fonte: Questionärio respondido por enfermeiros.

TABELA V

HOSPITAIS DO RIO DE JANEIRO

FREQU̇ÊNCIA DA AVALIAÇÃO DE DESEMPENHO DO SERVIDOR QUE ESTUDA ENFERMAGEM

1981

\begin{tabular}{|c|c|c|}
\hline NIVEL DE DESEMPENHO & FREQUENCIA & $\%$ \\
\hline EXCELENTE & 05 & 11,9 \\
\hline Вом & 09 & 21,4 \\
\hline SATISFATORIO & 09 & 21,4 \\
\hline DEFICIENTE & 14 & 33,4 \\
\hline INSUFICIENTE & 05 & 11,9 \\
\hline PESSIMO & 00 & - \\
\hline $\begin{array}{lllll}T & 0 & T & A & L\end{array}$ & 42 & 100,0 \\
\hline
\end{tabular}

Fonte: Questionário respondido por Enfermeiros Supervisores. 
COSTA, Z.S. e Colaboradoras - Estudo de Alguns Fatores que Influenciam o Rendimento Escolar do Estudante de Enfermagem. Rev. Bras. Enf.; DF, 35 : 102-130, 1982.

T A B E L A V I

HOSPITAIS DO RIO DE JANEIRO

FREQƯENCIA DA AVALIAÇĀO DE ATITUDES DO SERVIDOR-ESTUDANTE DE ENFERMAGEM

1981

\begin{tabular}{|c|c|c|c|c|c|c|}
\hline \multicolumn{2}{|c|}{ ATITUDES } & \multirow{2}{*}{$\begin{array}{c}\text { FREQUENCIA } \\
02\end{array}$} & \multirow{2}{*}{\multicolumn{2}{|c|}{$\begin{array}{l}7 \\
4,8\end{array}$}} & \multicolumn{2}{|c|}{ SEM RESPOSTA } \\
\hline A TIVO & & & & & 3 & 7,1 \\
\hline INTERESS & SADO & 04 & & 9,5 & . & $\ldots$ \\
\hline CANSADO & & 27 & & 64,3 & . & $\ldots$ \\
\hline DESINTER & RESSADO & 05 & & 11,9 & . & $\ldots$ \\
\hline \multirow[t]{2}{*}{ OMISSO } & (*) & 01 & & 2,4 & . & $\cdots$ \\
\hline & T O T A L & 39 & & 92,9 & 3 & 7,1 \\
\hline \multirow[t]{2}{*}{ Fonte: } & $\begin{array}{l}\text { Questionário } \\
\text { visores. }\end{array}$ & respondido & por & Enfe & meiros & Super- \\
\hline & $\begin{array}{l}\text { (*) Interess } \\
\text { tudantis }\end{array}$ & dos apenas & em & cumpr & r tare & fas es- \\
\hline
\end{tabular}

T A B E L A VII

CENTRO DE CIENCIAS DA SAÚDE - CURSO DE ENFERMAGEM FREQUUENCIA DAS CAUSAS PROVAVEIS DAS DIFICULDADES ENCONTRADAS PELOS ESTUDANTES DURANTE O CURSO 1981

\begin{tabular}{cccc}
\hline CAUSAS PROVAVEIS & $\begin{array}{c}\text { No DE } \\
\text { ESTUDANTES }\end{array}$ & $\%$ \\
\hline FALTA DE TEMPO PARA ESTUDAR & 95 & 25,2 * \\
CANSAÇO PELO TRABALHO & 76 & 20,2 * \\
FALTA DE TEMPO PARA DORMIR & 135 & 35,9 * \\
$\begin{array}{l}\text { SITUAÇÃO ECONÔMICA INSUFI- } \\
\text { CIENTE }\end{array}$ & 70 & 18,7 \\
& T O T A L & 376 & 100,0
\end{tabular}

Fonte: Questionário respondido pelos estudantes do Curso de Enfermagem da UNI-RIO.

(*) pressupõem-se os que trabalham em serviço no turno. 
COSTA, Z.S. e Colaboradoras - Estudo de Alguns Fatores que Influenciam o Rendimento Escolar do Estudante de Enfermagem. Rev. Bras. Enf.; DF, 35 : 102-130, 1982.

TABELA VIII

HOSPITAIS DO RIO DE JANEIRO

FREQUUENCIA DAS CAUSAS PROVAVEIS DAS DIFICULDADES

ENCONTRADAS PELOS GRADUADOS EM ENFERMAGEM

QUANDO ESTUDANTE

$1951-1979$

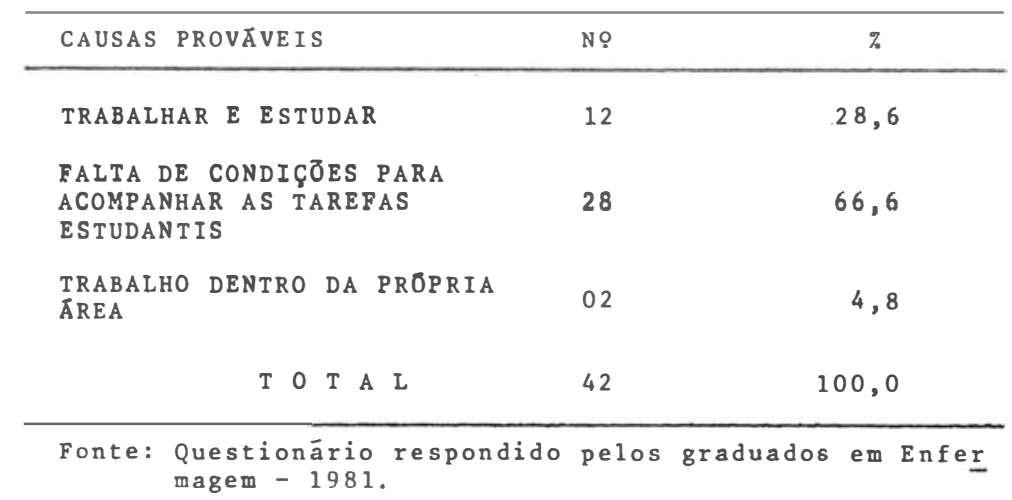

T A B E L A I X

HOSPITAIS DO RIO DE JANEIRO

FREQÜENCIA DAS OPINIÕES DE SUPERVISORES EM ENFERMAGEM SOBRE DIFERENTES ATIVIDADES COMPATÍVEIS COM AS ESTUDANTIS

1981

\begin{tabular}{llccc}
\hline A T I V I D A D E S & TOTAL & $\%$ & SEM RESPOSTA \\
\hline $\begin{array}{l}\text { ESTUDAR E TRABALHAR EM QUAL } \\
\text { QUER TIPO DE SERVIÇO }\end{array}$ & $\ldots$ & $\ldots$ & $\ldots$ & $\ldots$ \\
APENAS ESTUDAR & 21 & 50 & 02 & 4,8 \\
$\begin{array}{l}\text { TRABALHAR EM ENFERMAGEM E } \\
\text { ESTUDAR }\end{array}$ & 14 & 33,3 & $\ldots$ & $\ldots$ \\
$\begin{array}{l}\text { TRABALHAR EM ATIVIDADES SIM } \\
\text { PLES E ESTUDAR }\end{array}$ & 05 & 11,9 & $\ldots$ & $\ldots$ \\
T O T A L & 40 & 95,2 & 02 & 4,8 \\
\hline
\end{tabular}

Fonte:Questionärio respondido pelos Supervisores em Enfermagem. 
COSTA, Z.S. e Colaboradoras - Estudo de Alguns Fatores que Influenciam o Rendimento Escolar do Estudante de Enfermagem. Rev. Bras. Enf.; DF, $35: 102-130,1982$.

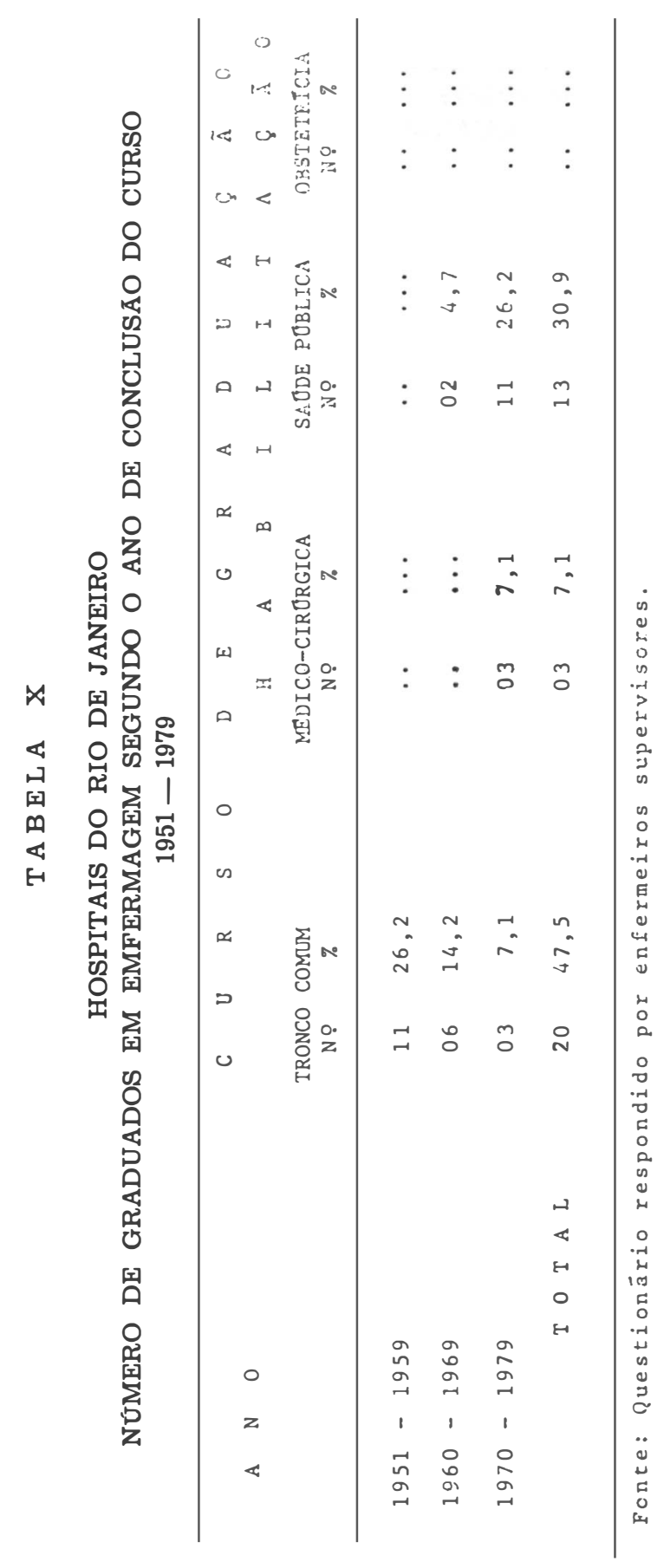


COSTA, Z.S. e Colaboradoras - Estudo de Alguns Fatores que Influenciam o Rendimento Escolar do Estudante de Enfermagem. Rev. Bras. Enf.; DF, 35 : 102-130, 1982.

TABELA XI

HOSPITAIS DO RIO DE JANEIRO

NÚMERO DE GRADUADOS EM ENFERMAGEM POR FAIXA ETÁRIA

$1951-1979$

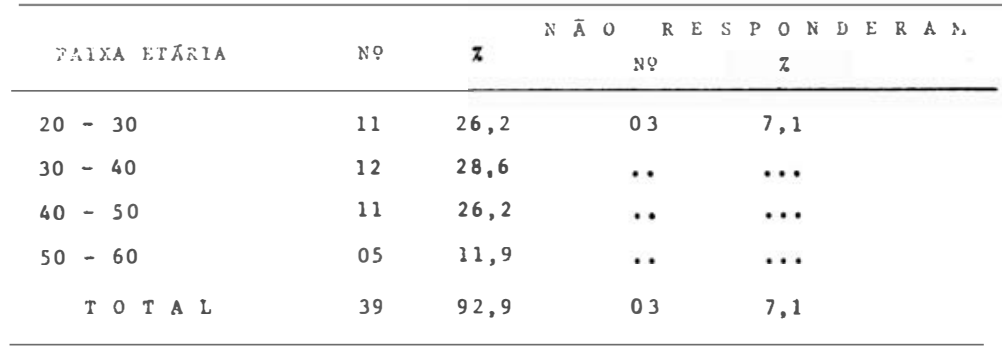

Ponte: Questionário respondido por enfermeiros supervisores.

T A B E L X I I

HOSPITAIS DO RIO DE JANEIRO

NÚMERO DE GRADUADOS QUE DURANTE O CURSO DE ENFERMAGEM EXERCIAM OUTRAS ATIVIDADES $1951-1979$

\begin{tabular}{|c|c|c|}
\hline TURNO DAS ATIVIDADES & № DE GRADUADOS & 7 \\
\hline NOTURNO & 27 & 64,3 \\
\hline DI ORNO & 12 & 28,6 \\
\hline VESPERTINO & $\ldots$ & $\ldots$ \\
\hline PARCIAL & 02 & 4,8 \\
\hline LIVRE & 01 & 2,3 \\
\hline $\begin{array}{lllll}\mathrm{T} & 0 & \mathrm{~T} & \mathrm{~A} & \mathrm{~L}\end{array}$ & 42 & 100,0 \\
\hline
\end{tabular}

Fonte: Questionārio respondido pelos enfermeiros supervisores.

TABELA XIII

CENTRO DE CIENCIAS DA SAÚDE - CURSO DE ENFERMAGEM NUMERO DE DOCENTES QUE TRABALHARAM DURANTE

O CURSO DE ENFERMAGEM

$1940-1979$

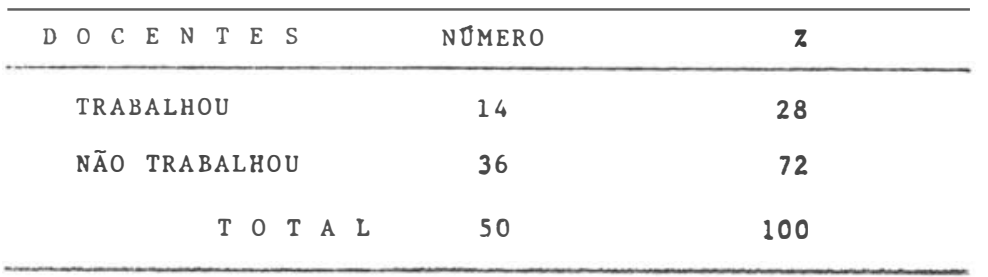

Fonte: Questionário respondido pelos docentes da UNI-RIO. 
COSTA, Z.S. e Colaboradoras - Estudo de Alguns Fatores que Influenciam o Rendimento Escolar do Estudante de Enfermagem. Rev. Bras. Enf.; DF, 35 : 102-130, 1982.

TABELA XIV

CENTRO DE CIÊNCIAS DA SAÚDE - CURSO DE ENFERMAGEM NÚMERO DE DOCENTES DE ACORDO COM A FAIXA ETÁRIA

$1940-1979$

\begin{tabular}{rcc}
\hline FAIXA ETARIA & NOMERO & $\%$ \\
\hline $20-30$ & 10 & 20 \\
$30-40$ & 06 & 12 \\
$40-50$ & 24 & 48 \\
$50-60$ & 10 & 20 \\
T O T A L & 50 & 100 \\
\hline
\end{tabular}

Fonte:Questionário respondido pelos docentes da UNI-RIO.

TABELA X V

CENTRO DE CIENCIAS DA SAÚDE - CURSO DE ENFERMAGEM DISTRIBUIÇÃO DOS DOCENTES SEGUNDO ATIVIDADES DESENVOLVIDAS ALEM DO CURSO DE ENFERMAGEM $1940-1979$

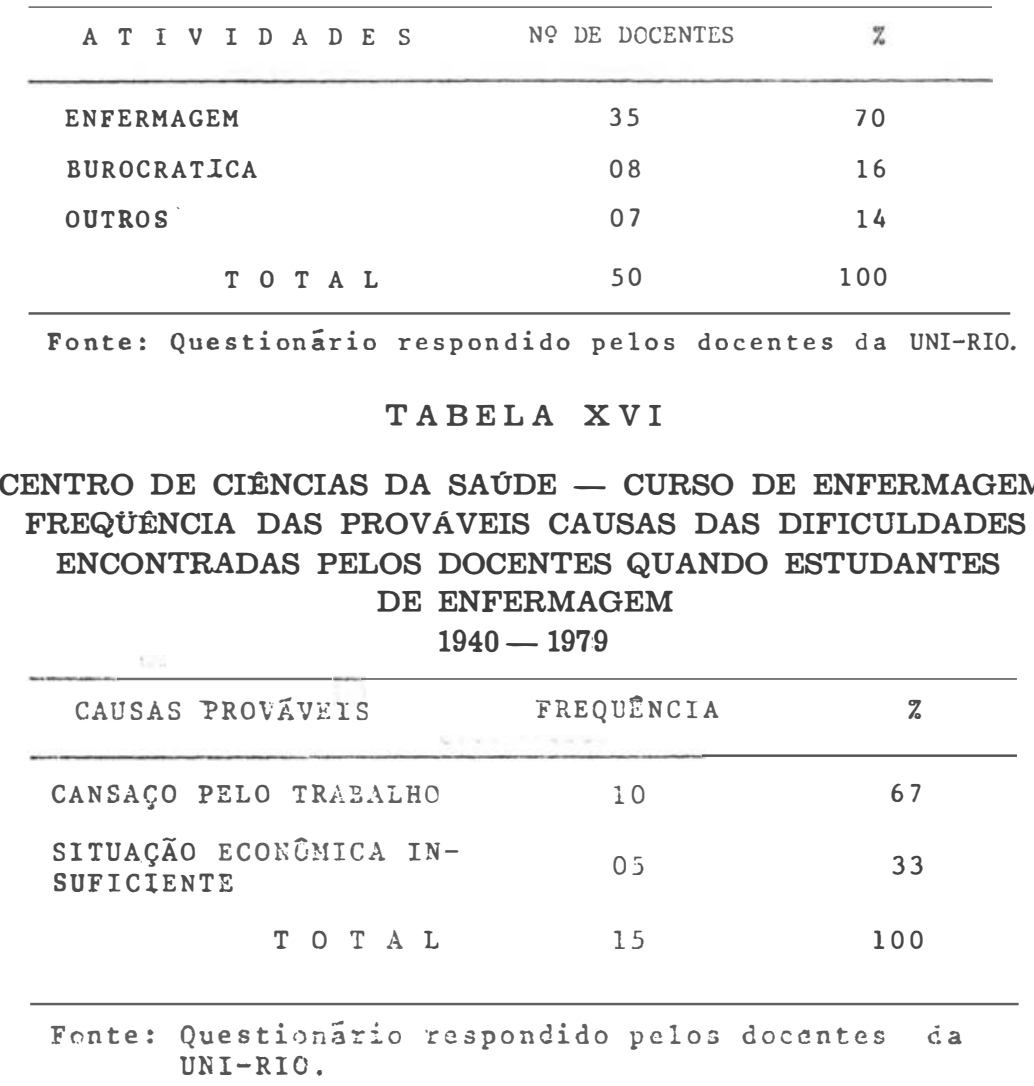


COSTA, Z.S. e Colaboradoras - Estudo de Alguns Fatores que Influenciam o Rendimento Escolar do Estudante de Enfermagem. Rev. Bras. Enf.; DF, 35 : 102-130, 1982.

TABELA XVII

CENTRO DE CIENCIAS DA SAÚDE - CURSO DE ENFERMAGEM FREQUUÊNCIA DAS OPINIOEES DOCENTES QUANTO AS INFLUÊNCIAS DA AREA DE ATUAÇÃO SOBRE O ESTUDANTE NO PROCESSO ENSINO-APRENDIZAGEM

\begin{tabular}{|c|c|c|}
\hline \multicolumn{3}{|c|}{$1940-1979$} \\
\hline OPINIÕES DOCENTES & FREQUENCIA & $\%$ \\
\hline SOFRE INFLUENCIA & 45 & 90 \\
\hline NÃO SOFRE & 05 & 10 \\
\hline $\mathrm{T} \quad 0 \quad \mathrm{~T} \quad \mathrm{~A} \quad \mathrm{~L}$ & 50 & 100 \\
\hline
\end{tabular}

T A B ELA X V I I I

CENTRO DE CIENCIAS DA SAÚDE - CURSO DE ENFERMAGEM FREQUUENCIA DE OPINIŌES DOCENTES SOBRE O DESEMPENHO DISCENTE 1981

\begin{tabular}{|c|c|c|}
\hline NIVEL DE FREQUENCIA & FREQUENCIA & $\pi$ \\
\hline BOM & 08 & 16 \\
\hline DEFICIENTE & 28 & 56 \\
\hline INSUFICIENTE & 14 & 28 \\
\hline$T O P A L$ & 50 & 100 \\
\hline
\end{tabular}

T A B E L A XIX

CENTRO DE CIENCIAS DA SAÚDE - CURSO DE ENFERMAGEM FREQUUENCIA DE OPINIŌES DOCENTES SOBRE ATITUDES ESTUDANTIS DURANTE SUAS ATIVIDADES CURRICULARES 1981

\begin{tabular}{|c|c|c|}
\hline $\begin{array}{c}\text { OPINIOEES SOBRE } \\
\text { ATITUDES DISCENTES }\end{array}$ & FREQUENCIA & $\%$ \\
\hline CANSADOS & 32 & 64 \\
\hline DESINTERESSADOS & 16 & 32 \\
\hline INTERESSADOS & 02 & 4 \\
\hline $\mathrm{T} \quad 0 \mathrm{~T} A \mathrm{~L}$ & 50 & 100 \\
\hline
\end{tabular}


COSTA, Z.S. e Colaboradoras - Estudo de Alguns Fatores que Influenciam o Rendimento Escolar do Estudante de Enfermagem. Rev. Bras. Enf.; DF, 35 : 102-130, 1982.

T A B E L A X X

CENTRO DE CIENCIAS DA SAÚDE - CURSO DE ENFERMAGEM FREQUENCIA DAS OPINIŐES DOS DOCENTES QUANTO AS ATIVIDADES COMPATIVEIS COM AS ESTUDANTIS 1981

\begin{tabular}{lcc}
\hline ATIVIDADES & FREQUENCIA & $\%$ \\
\hline APENAS ESTUDAR & 42 & 84 \\
$\begin{array}{l}\text { TRABALHAR EM ATIVIDADES } \\
\text { SIMPLES E ESTUDAR }\end{array}$ & 0,8 & 16 \\
T O T A L & 50 & 100 \\
\hline
\end{tabular}

Fonte: Questionārio respondido pelos docentes da UNI - RIO.

T A BELA XXI

CENTRO DE CIENCIAS DA SAÚDE - CURSO DE ENFERMAGEM FREQUENCIA DE ESTUDANTES QUE TRABALHAM PARA

O SEU PRÓPRIO SUSTENTO

1981

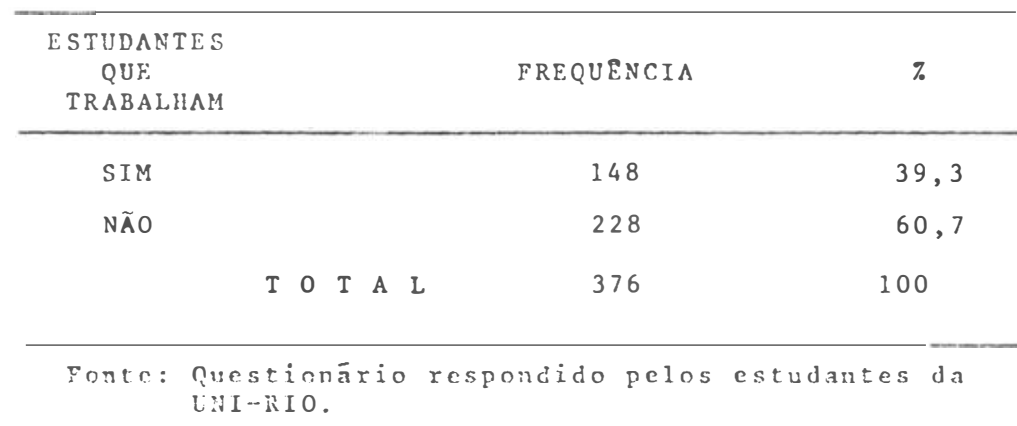

TABELA XXII

CENTRO DE CIENCIAS DA SAÚDE - CURSO DE ENFERMAGEM NUMERO DE ESTUDANTES DE ENFERMAGEM CUJOS GASTOS SÃO FINANCIADOS PELA FAMILIA E OUTROS * 1981

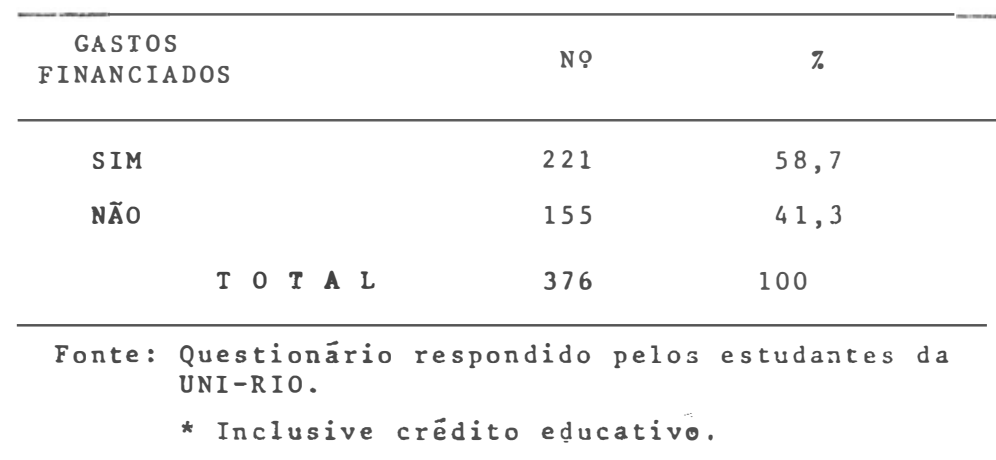


COSTA, Z.S. e Colaboradoras - Estudo de Alguns Fatores que Influenciam o Rendimento Escolar do Estudante de Enfermagem. Rev. Bras. Enf.; DF, 35 : 102-130, 1982.

TABELA XXIII

CENTRO DE CIÊNCIAS DA SAÚDE - CURSO DE ENFERMAGEM FREQUENECIA DE ESTUDANTES QUE CONTRIBUEM PARCIALMENTE PARA O SUSTENTO DA FAMILIA

1981

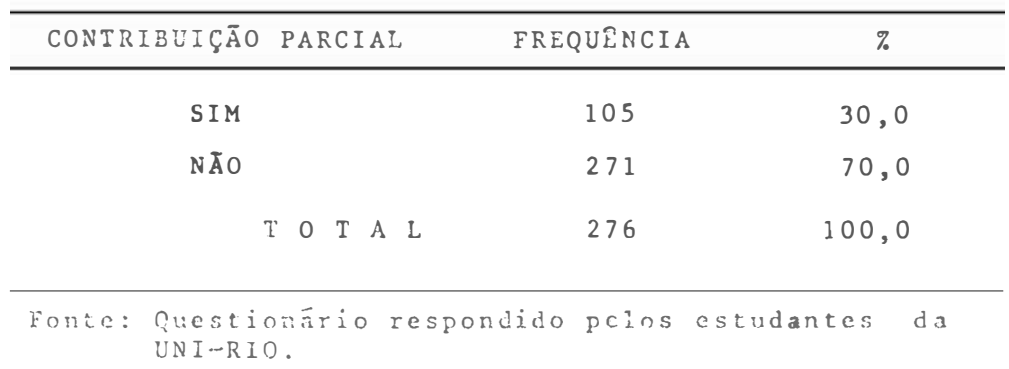

TABELA XXIV

CENTRO DE CIÊNCIAS DA SAÚDE - CURSO DE ENFERMAGEM FREQUTENCIA DAS OPINIÓES DOS ESTUDANTES SOBRE A CONCILIAÇÃO TRABALHO-ESTUDO, NO CURSO DE ENFERMAGEM 1981

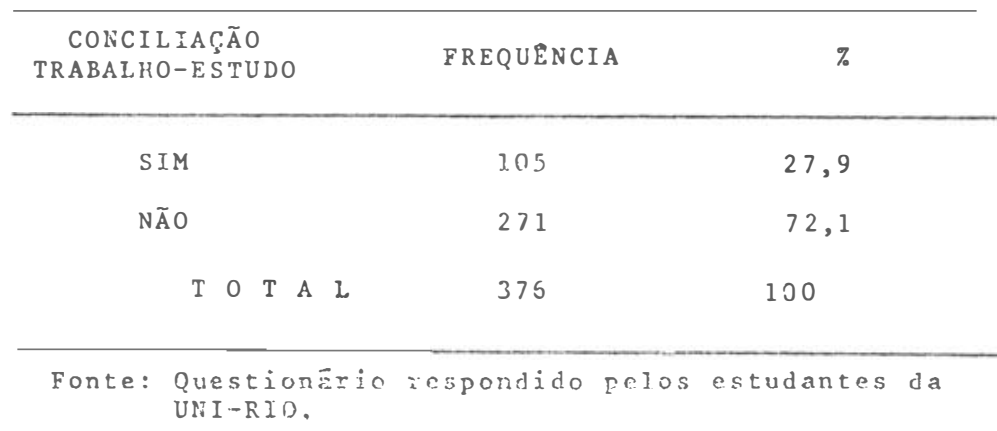


COSTA, Z.S. e Colaboradoras - Estudo de Alguns Fatores que Influenciam o Rendimento Escolar do Estudante de Enfermagem. Rev. Bras. Enf.; DF, 35 : 102-130, 1982.

OPERACIONALIZAÇĀO DO ENSINO

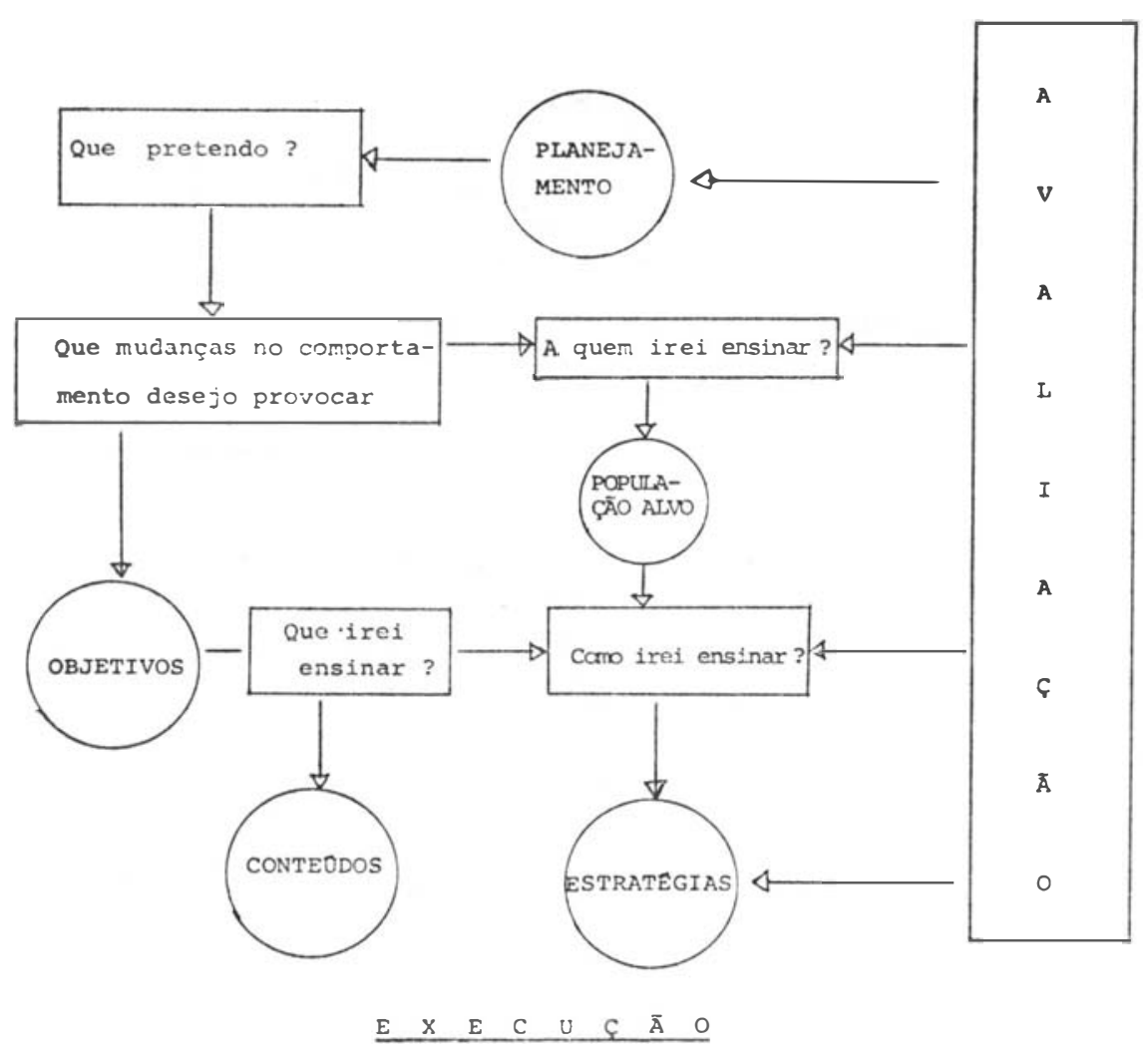

o desenvolvimento deste plano serä executado com as modificações que a prática for impondo, para tå a avaliaçāo é a fase seguintu:

\begin{tabular}{llllllllll}
$A$ & $\mathbf{V}$ & $A$ & $L$ & $I$ & $A$ & $C$ & $\AA$ & 0 \\
\hline
\end{tabular}

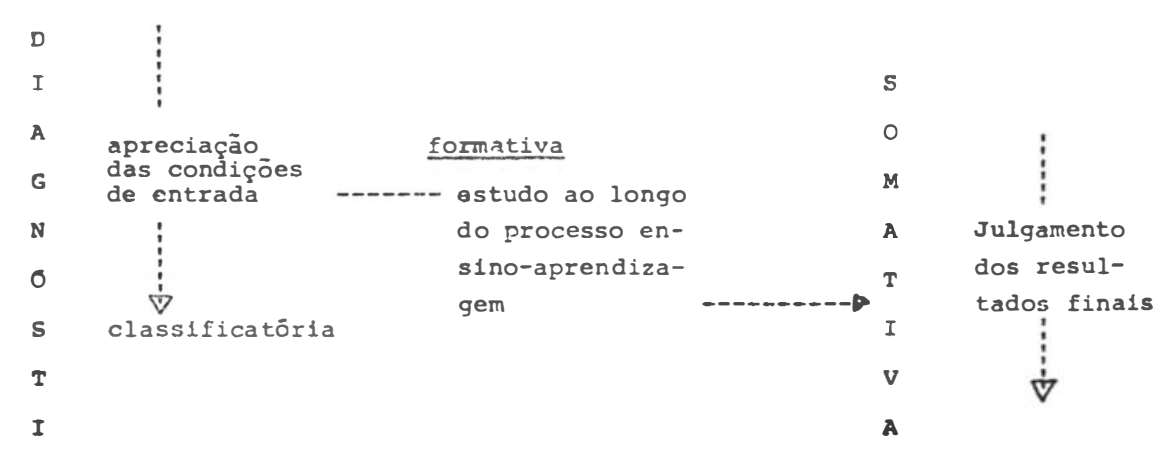

A 